\title{
RESPON FISIOLOGIS PASIEN PASCA OPERASI CAESAR SETELAH TERAPI MUROTAL AR RAHMAN
}

\author{
Ikit Netra Wirakhmi ${ }^{1}$, Arlyana Hikmanti ${ }^{2}$ \\ 1,2Dosen Program Studi D3 Kebidanan STIKES Harapan Bangsa Purwokerto \\ email: ikitnetra@yahoo.co.id
}

\begin{abstract}
Pain results in sympathetic stimulation, which leads to releasing of epinephrine, and affects in rapid heart rate, rapid and shallow breathing, increased artheries pressure. Selected drugs for pain promote side effects such as nausea, vomiting and dependence. A nonpharmacological such as reciting Quran is required. This study was to examine the effect listening recited Ar Rahmaan on physiological responses among post section caesarean patients in dr. Goeteng Hospital. A quasy experimental study with Control Group pre-test and post-test desing was conducted. A consecutive sampling recruited 40 respondents divided into a control group (20) and treatment (20). The treatment group accepted standard therapy plus listening Ar Rahman murotal therapy for 13 minutes 55 seconds once. While the control group accepted standard therapy. Measurements conducted before and after the treatments. Changes of physical responses were analysed by Wilcoxon and Paired Samples t-test. Then, the differences in physiological responses changes and pain intensity between two groups were analysed Mann Whitney test. Results showed a significant differences in blood pressure between before and after treatment both in the control group and the treatment with $p$ systole 0.003 and $p$ diastole 0.018 . However, there were no significant differences on the pulse rate and respiratory rate $p(0.429$ and 0,0666$)$ respectively. It concluded that among post section cesarean patients murotal Ar Rahman decreased blood pressure but not it was not for pulse and respiratory rate.
\end{abstract}

Keywords: murotal Ar Rahman, physiological responses, post SC

\section{ABSTRAK}

Stimulasi simpatik oleh nyeri menyebabkan pelepasan epineprin ditandai denyut jantung cepat, pernafasan cepat dan dangkal, dan peningkatan tekanan arteri. Sedangkan obat Terapi non farmakologik, salah satunya dengan bacaan Al Qur'an dapat membantu. Penelitian ini untuk menguji efek terapi murotal Ar Rahmaan terhadap respon fisiologis pasien pasca operasi caesar di RSUD dr. R. Goeteng. Penelitian Quasy Experimental dengan rancangan pre-test and post-test design control group dilakukan. Consecutive sampling memperoleh 40 responden dibagi dalam kelompok kontrol (20) dan perlakuan (20). Kelompok perlakuan mendapatkan terapi standar dan terapi murotal Surat $\mathrm{Ar}$ Rahman selama 13 menit 55 detik sebanyak satu kali. Hasil pengukuran sebelum dan sesudah terapi dianalisis dengan uji Wilcoxon dan Paired Samples Test. Perubahan respon fisiologis dan intensitas nyeri antara kedua kelompok dianalisis dengan uji Mann Whitney. Hasil penelitian menunjukkan ada perbedaan bermakna tekanan darah antara sebelum dan sesudah perlakuan pada kedua kelompok ( $p$ sistole 0,$003 ; p$ diastole 0,018 ), tetapi frekuensi nadi dan pernapasan tidak menjukkan perbedaan bermakna dengan nilai $p$ berturutan $(0,429 ; 0,666)$. Disimpulkan bahwa ada pengaruh murotal Ar Rahman terhadap penurunan tekanan darah pasien pasca operasi caesar tetapi tidak demikian pada penurunan frekuensi nadi dan pernapasan.

Kata Kunci: murotal Ar Rahman, respon fisiologis, pasca SC 


\section{LATAR BELAKANG}

Persalinan merupakan proses fisiologis dari uterus untuk mengeluarkan hasil konsepsi. Persalinan bisa berjalan secara normal, namun apabila proses persalinan mengalami hambatan maka harus dilakukan operasi. Sectio caesarea (SC) merupakan salah satu cara yang digunakan untuk membantu proses persalinan ketika tidak bisa dilakukan secara normal (Jitowiyono \& Kristiyanasari, 2010).

Tindakan SC menyebabkan terjadinya perubahan kontinuitas jaringan tubuh. Pada proses SC digunakan anastesi agar pasien tidak merasakan nyeri, namun setelah operasi selesai dan pasien mulai sadar, pasien akan merasakan nyeri pada bagian tubuh yang mengalami pembedahan. Nyeri adalah pengalaman sensori dan emosi yang tidak menyenangkan yang berhubungan dengan kerusakan jaringan yang bersifat aktual atau potensial (Yuliatun, 2008).

Nyeri menimbulkan dampak buruk terhadap proses penyembuhan luka SC. Nyeri yang dirasakan oleh pasien pasca SC sering menjadi alasan untuk tidak melakukan mobilisasi dini. Mobilisasi dini bertujuan untuk mempercepat proses penyembuhan luka, mempercepat involusi alat kandungan, melancarkan fungsi alat gastrointestinal dan alat perkemihan serta meningkatkan kelancaran peredaran darah (Cuningham, 2006). Oleh karena itu, penanganan nyeri pasca SC sangat penting untuk dilakukan.

Efek membahayakan dari nyeri dibedakan berdasarkan klasifikasi nyeri, yaitu nyeri akut dan nyeri kronis. Selain merasa ketidaknyamanan dan mengganggu, nyeri akut yang tidak reda dapat mempengaruhi sistem pulmonary, kardiovaskular,

gastrointestinal, endokrin, dan immunologik (Smeltzer dan Bare, 2012).

Salah satu respon yang dimanifestasikan oleh tubuh dengan adanya stimulasi nyeri adalah respon fisiologis (respon simpatis dan parasimpatis). Nyeri mengakibatkan stimulasi simpatik, yang akan menyebabkan pelepasan epineprin, adanya peningkatan epineprin mengakibatkan denyut jantung cepat, pernafasan cepat dan dangkal, tekanan pada arteri meningkat (Potter dan Perry, 2010).

Banyak pasien dan tenaga kesehatan cenderung menganggap obat sebagai satu-satunya metode menghilangkan nyeri. Pemberian obat analgesik memiliki efek samping yang merugikan seperti mual, muntah dan ketergantungan sehingga dapat menimbulkan permasalahan baru bagi pasien yaitu resiko kekurangan nutrisi. Nutrisi merupakan elemen penting dalam proses penyembuhan luka. Oleh karena itu diperlukan metode nonfarmakologi yang mampu mengatasi nyeri secara efektif tanpa disertai efek samping (Martorella et al, 2008). Salah satu tindakan nonfarmakologis untuk mengatasi nyeri adalah distraksi pendengaran melalui murotal Al Quran (Al Kaheel, 2012).

Terapi murotal merupakan terapi religi dimana seseorang dibacakan ayatayat Al'Quran selama beberapa menit atau jam sehingga memberikan dampak positif bagi tubuh seseorang Gusmiran. 2005). Terapi murotal mampu memberikan ketentraman, ketenangan dan mengurangi kecemasan. Kondisi tentram dan nyaman ini akan menstimulasi pengeluaran neurotransmitter analgesia (endorphin, enkhepalin, dinorphin) sehingga mengurangi rasa nyeri (Qadri, 2003; 
Izzat \& Arif, 2011; Nurliana, 2011; Elzaky, 2011; Sodikin, 2012; Ras \& Laird, 2011).

Salah satu surat dalam Al Qur'an yang dapat digunakan sebagai terapi murotal adalah surat Ar Rahmaan (Salim, 2012). Surat Ar Rahmaan memiliki banyak ayat yang dibaca berulang-ulang sehingga dapat mengalihkan perhatian dan berfungsi sebagai hipnosis yang menurunkan gelombang otak pasien. Pada kondisi ini, otak akan memproduksi hormon serotonin dan endorfin yang membuat seseorang merasa nyaman, tenang dan bahagia (Gunawan, 2009). Secara fisiologis, keadaan relaksasi ditandai dengan penurunan kadar epinefrin dan non epinefrin dalam darah, penurunan frekuensi denyut jantung (sampai mencapai 24 kali per menit), penurunan tekanan darah, penurunan frekuensi nafas (sampai 4-6 kali per menit), penurunan ketegangan otot, metabolisme menurun, vasodilatasi dan peningkatan temperature pada extermitas.

Surat Ar Rahman mempunyai timbre medium, pitch $44 \mathrm{~Hz}$, harmony regular dan consistent, rythm andate (mendayu-dayu), volume 60 decibel, intensitas medium amplitudo, sehingga mempunyai efek relaksasi jika diperdengarkan pada pasien. Karakteristik Surat Ar Rahman Ahmad Saud telah divalidasi di laboratorium seni Fakultas Budaya dan Seni Universitas Negeri Semarang. Uji reliabilitas MP3 Surat Ar Rahman menunjukan setiap yang mendengarkan mendapatkan kualitas, durasi yang sama dari suara yang dihasilkan, karakteristik alat dan lantunan MP3 Surat Ar Rahman mempunyai efek terapeutik (Pramisiwi, dkk. 2011).

Berdasarkan data World Health Organization (WHO), selama tahun 2010 - 2011 terdapat 110.000 kelahiran di seluruh Asia dan 27 persen diantaranya dilakukan secara SC. Angka kejadian operasi SC di Indonesia adalah 921.000 dari $4.039 .000(22.8 \%)$ dan tahun 2010 adalah 734.000 dari 3.832 .000 persalinan (19.15\%) (Riskesdas. 2010). Kejadian operasi SC di Jawa Tengah mencapai 32.2\% (Litbangkes, 2012). Survey pendahuluan di RSUD dr. R. Goeteng Tarunadibrata Purbalingga diperoleh data angka kejadian SC pada tahun 2013 sebanyak 376 dari 1035 total persalinan $(36.32 \%)$ dan tahun 2014 sebanyak 336 orang dari 1167 total persalinan (28.79\%). Hal ini menunjukkan bahwa angka operasi SC di RSUD tersebut sudah melewati batas maksimal standar WHO yaitu $5-15 \%$ (Cuningham, 2006). Penanganan nyeri pasien pasca operasi SC menggunakan obat analgetik dan belum ada terapi nonfarmakologi.

\section{METODE PENELITIAN}

Desain penelitian yang digunakan dalam penelitian ini adalah Quasi Eksperiment dengan pendekatan Pretest-Posttest Control Group Design. Teknik pengambilan sampel dalam penelitian ini adalah consecutive sampling. Jumlah sampel dalam penelitian ini adalah 40 responden yang terbagi dalam dua kelompok, yaitu kelompok kontrol (20 responden) dan perlakuan (20 responden). Penelitian ini dilakukan dari tanggal 29 April - 03 Juni 2016. Lokasi penelitian adalah di ruang nifas RSUD dr.R. Goeteng Tarunadibrata Purbalingga. 


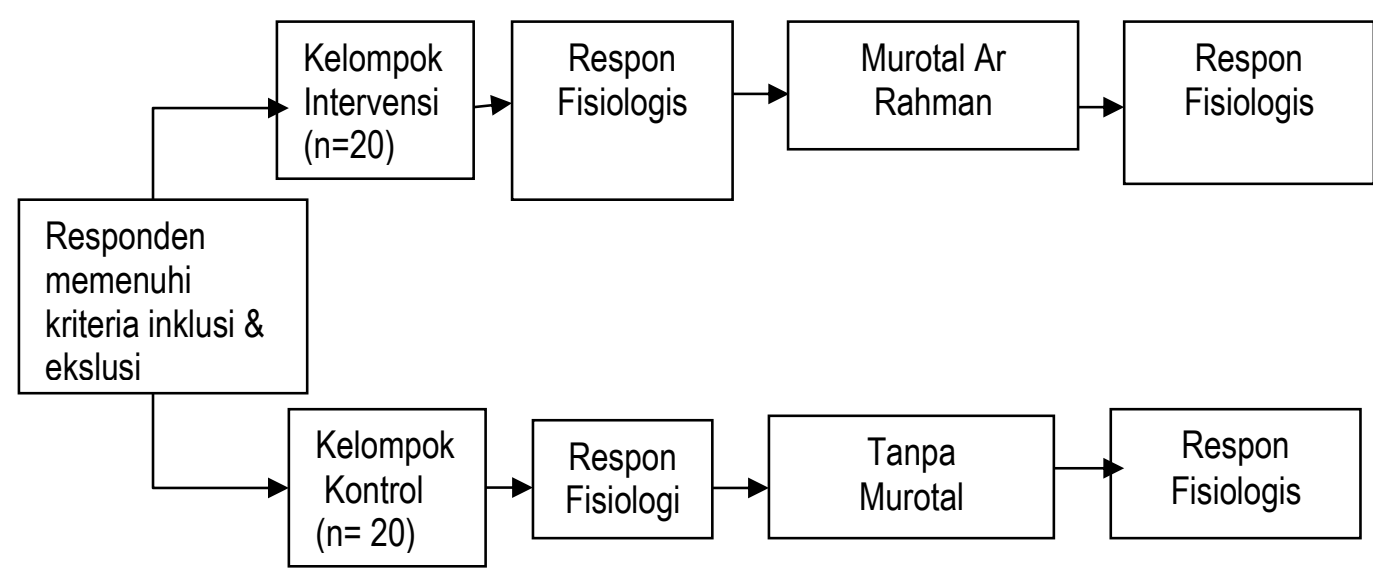

Grafik 1 Alur Penelitian

Kriteria inklusi dalam penelitian ini yaitu 1) Beragama islam, 2) Suku Jawa 3) Pasca operasi SC hari kedua, 4) Pasien SC untuk pertama kalinya, dan 5) Pasien yang didampingi oleh keluarganya. Kriteria eksklusi dalam penelitian ini yaitu 1) Mendapatkan pengobatan komplementer lain dan 2) Pasien yang menolak untuk menjadi responden

Penelitian ini memberikan perlakuan terapi dengan memperdengarkan murotal Ar Rahman yang dilantunkan Ahmad Saud melalui headphone selama 13 menit 55 detik pada $5-7$ jam setelah diberikan terapi farmakologik.

Dilakukan analisis data untuk mengetahui perbedaan penurunan respon fisiologis antara kedua kelompok. Uji paired sample test digunakan untuk mengetahui perbedaan rerata nilai respon fisiologis sebelum dan sesudah intervensi dan observasi pada kelompok kontrol maupun intervensi untuk data berdistribusi normal. Uji Wilcoxon digunakan untuk data yang berdistribusi tidak normal. Uji yang digunakan untuk mengetahui perbedaan penurunan nilai respon fisiologis kelompok kontrol dan intervensi dengan data berdistribusi normal adalah uji t tidak berpasangan. Uji Mann Whitney digunakan untuk data yang tidak berdistribusi normal (Dahlan, 2013).

\section{HASIL DAN PEMBAHASAN}

\section{Karakteristik responden berdasarkan umur dan paritas}

Grafik 2 menunjukkan bahwa kategori usia dan paritas untuk kelompok perlakuan dan kontrol adalah setara atau homogen. Mayoritas responden berusia antar 20-25 tahun (20 orang) dan kehamilan multipara (24 orang). Responden dengan kehamilah primipara hampir setengah responden (16 orang). Respon fisiologis pada pengukuran kedua cenderung turun. 


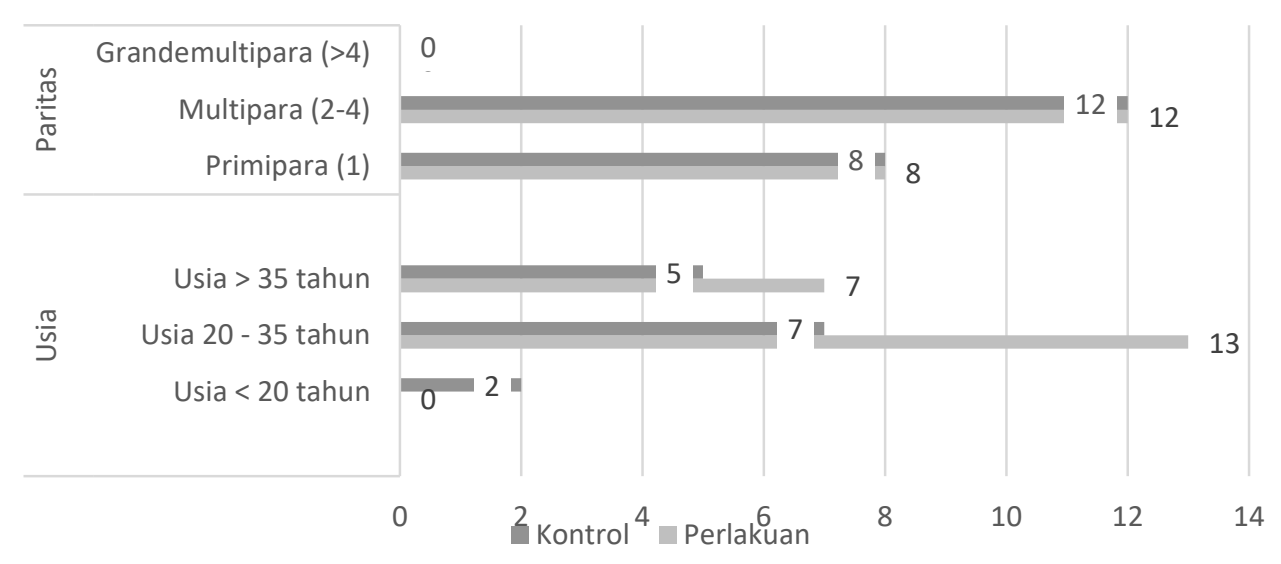

Grafik 2. Karakteristik Responden

Kelompok kontrol menunjukkan tekanan systole turun dari 120,5 ke 120 $\mathrm{mmHg}$. Tekanan diastole turun dari 80 ke $79,5 \mathrm{mmHg}$. Frekuensi nadi turun dari 85 ke 84,5 kali per menit. Frekuensi pernapasan turun dari 24 ke 22,5. Sedangkan pada kelompok intervensi tekanan systole dan diastole turun lebih tajam. Tekanan systole dari 129 ke 123,5 $\mathrm{mmHg}$, tekanan diastole dari 83,5 ke 80 $\mathrm{mmHg}$. Frekuensi nadi tidak terlalu berbeda dari 87,5 ke 86 kali per menit. Demikian juga dengan frekuensi pernapasan turun dari 23 ke 22 kali per menit.

Perbedaan penurunan respon fisiiologi (table 1). Penurunan tekanan systole, tekanan diastole, frekuensi nadi dan frekuensi napas kelompok kontrol secara berurutan padalah 0,$5 ; 0 ; 1,5$; dan 1 poin. Sedangkan pada kelompok. Sedangkan pada kelompok intervensi penurunan tekanan systole, diastole, frekuensi nadi dan frekuensi penapasan secara berurutan adalah $4 ; 3 ; 2$; dan 1 poin. Penurunan respon pada kelompok perlakuan cenderung lebih besar.

\section{Perbedaan Penurunan Respon Fisiologis pada Kelompok Kontrol dan Perlakuan}

Hasil uji statistik menunjukkan bahwa terdapat perbedaan bermakna penurunan tekanan darah antara kelompok kontrol dengan perlakuan dengan nilai tekanan sistole $p=0.003$, tekanan diastole $p=0.018(p>0.05)$ namun tidak terdapat perbedaan bermakna penurunan frekuensi nadi dan pernafasan antara kelompok kontrol dengan perlakuan dengan nilai frekuensi nadi $p=0.429$ dan frekuensi respirasi $p$ $=0.666$.

Karakteristik surat Ar Rahman yang dilantunkan oleh Ahmad Saud telah divalidasi di laboratorium seni Fakultas Budaya dan Seni Universitas Negeri Semarang. Surat $\mathrm{Ar}$ Rahman mempunyai timbre medium, pitch $44 \mathrm{~Hz}$, harmony regular dan consistent, rythm andate (mendayu-dayu), volume 60 decibel, intensitas medium amplitudo (Pramisiswi dkk, 2011).

Rhytm adalah tempo atau durasi. Pada pitch yang rendah dengan rhythm yang lambat dan volume yang rendah akan menimbulkan efek rileks (Wilgram, 2002 dan Chiang L, 2012). Frekuensi mengacu pada tinggi dan 


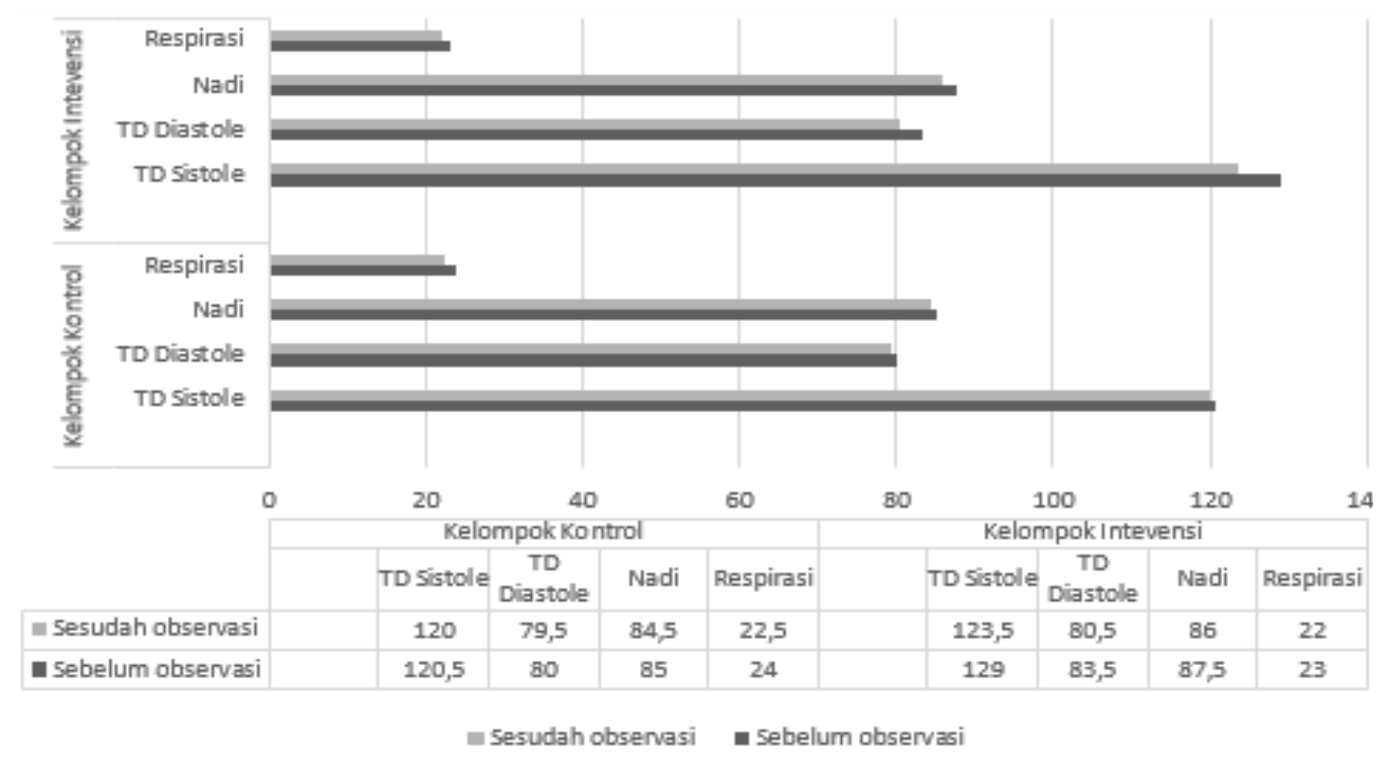

Grafik 2. Respon Fisiologis Sebelum dan Sesudah Perlakuan

rendah nada serta tinggi rendahnya kualitas suara yang diukur dalam Hertz, yaitu jumlah daur perdetik dimana gelombang bergetar. Telinga manusia memiliki sensitifitas mendengar pada kisaran $20-20.000 \mathrm{~Hz}$. Erkainen melakukan penelitian frekuensi suara yang bisa dijadikan terapi (Erkainen, 2007). Frekuensi yang telah terbukti untuk mengurangi nyeri pasca operasi dan menimbulkan efek tenang adalah 40 - $60 \mathrm{~Hz}$ (Arslan dkk, 2007; AMTA, 2008 dan Mitas, 2009).

Decibel $(\mathrm{dB})$ adalah satuan volume untuk mendengarkan getaran suara. Volume yang bisa menimbulkan efek teraupetik adalah 40-60 dB (Perdana dan Niswah, 2011). Hasil penelitian menunjukkan bahwa terapi audio lembut $(60-70 \mathrm{~dB})$ dapat memberikan efek relaksasi secara general dibandingkan dengan yang diperdengarkan pada tingkat kebisingan lebih keras (Faradisi, 2012 dan Hady dkk, 2012). Sedangkan waktu yang dibutuhkan dalam auditoris therapy (terapi pendengaran) supaya dapat memberikan efek terapeutik adalah minimal selama 10 menit (Potter, P.A dan Perry A.G, 2010).

Surat Ar-Rahman merupakan salah satu surat dalam Al-Qur'an yang terdiri atas 78 ayat. Semua ayat dalam surat Ar-Rahman merupakan surat yang mempunyai karakter ayat pendek sehingga ayat ini nyaman didengarkan dan dapat menimbulkan efek relaksasi bagi pendengar yang masih awam sekalipun. Bentuk gaya bahasa dalam surat Ar Rahman ini mempunyai ciri-ciri pengulangan ayat yaitu terdapat 31 ayat yang diulang-ulang. Pengulangan ayat ini untuk menekankan keyakinan yang sangat kuat (Sunny, 2014). Pengulangan ayat ini juga bisa merupakan suatu bentuk meditasi yaitu memusatkan pikiran pada satu obyek yang dilakukan dengan kesadaran penuh, dirasakan bagaimana proses itu berefek pada tubuhnya sehingga bisa menimbulkan efek relaksasi maupun sebagai penyembuhan pada tubuh (Muslih, 2006). Oleh karena itu pada saat pengambilan data terdapat beberapa pasien yang mengantuk bahkan sampai 
tertidur ketika diperdengarkan murotal $\mathrm{Ar}$ Rahman.

Hasil penelitian ini sesuai dengan penelitian Ernawati dan Sagiran (2013) yaitu mendengarkan murottal $\mathrm{Ar}$ Rahman berpengaruh terhadap pola tekanan darah pada pasien hipertensi di Rumah Sakit Nur Hidayah Yogyakarta. Hasil penelitian ini juga sesuai dengan penelitian yang dilakukan oleh Mahardika et al (2012) dengan judul yang hampir sama yaitu Pengaruh Terapi Murottal Terhadap Penurunan Tekanan Darah Pada Lansia Dengan Hipertensi di Desa Pagumenganmas Kecamatan Karangdadap Kabupaten Pekalongan menunjukkan bahwa ada pengaruh mendengarkan terapi murottal terhadap penurunan tekanan darah.

$$
\text { Pembedahan mengakibatkan }
$$

timbulnya respon stres berupa
perubahan hormonal dan metabolisme. Respon stress merupakan reaksi sistemik yang ditandai dengan peningkatan sekresi hormon hipofisis dan aktivasi sistem saraf simpatis, selanjutnya aktivitas sistem saraf simpatis menimbulkan peningkatan tekanan darah dan denyut jantung (Desborough, 2000 dalam Nafi'ah, 2015).

Mendengarkan Al-Qur'an akan memberikan efek ketenangan dalam tubuh sebab adanya unsur meditasi, autosugesti dan relaksasi yang terkandung didalamnya (Anwar, 2010 dalam Ernawati, 2013). Rasa tenang ini kemudian akan memberikan respon emosi positif yang sangat berpengaruh dalam mendatangkan persepsi positif. Persepsi positif yang didapat dari murottal Ar Rahman selanjutnya akan merangsang hipotalamus untuk mengeluarkan hormon endorfin, seperti yang kita tau hormon ini akan membuat seseorang merasa bahagia. Selanjutnya amigdala akan merangsang pengaktifan sekaligus pengendalian saraf otonom yang terdiri dari saraf simpatis dan parasimpatis. Saraf parasimpatis bersfungsi untuk mempersarafi jantung dan memperlambat denyut jantung, sedangkan saraf parasimpatis sebaliknya. Rangsangan saraf otonom yang terkendali akan menyebabkan sekresi epinefrin dan norepinefrin oleh medula adrenal menjadi terkendali pula. Terkendalinya hormon epinefrin dan norepinefrin akan menghambat pembentukan angiotensin yang selanjutnya dapat menurunkan tekanan darah (Mustamir, 2009 dalam Ernawati, 2013).

Hasil penelitian menunjukkan tidak terdapat perbedaan bermakna penurunan frekuensi nadi dan pernafasan antara kelompok kontrol dengan perlakuan. Hal ini disebabkan karena terdapat beberapa faktor yang mempengaruhi frekuensi nadi dan pernafasan yang tidak bisa dikontrol oleh peneliti. Beberapa faktor tersebut antara lain : circadian rhythm (rata-rata menurun pada pagi hari dan meningkat pada siang dan sore hari), bentuk tubuh (tinggi, langsing biasanya denyut jantung lebih pelan dan nadi lebih sedikit dibandingkan orang gemuk), stress dan emosi (rangsangan syaraf simpatis dan emosi seperti cemas, takut, gembira meningkatkan denyut jantung dan nadi), suhu tubuh (setiap peningkatan $10 \mathrm{~F}$ menunjukkan nadi meningkat $10 \mathrm{x} /$ menit, peningkatan $1^{\circ} \mathrm{C}$ menunjukkan nadi meningkat $15 \mathrm{x} /$ menit dan sebaliknya bila terjadi penurunan suhu tubuh maka nadi akan menurun), volume darah (kehilangan darah yang berlebihan akan menyebabkan peningkatan nadi) serta obat-obatan (beberapa obat dapat menurunkan atau meningkatkan kontraksi jantung seperti golongan 
digitalis, golongan sedative menurunkan frekuensi nadi sedangkan caffeine, nicotine, cocaline, hormone tyroid, adrenalin meningkatkan frekuensi nadi) (Mahrifatulhijah, 2014).

\section{KESIMPULAN}

Sebagian besar responden pada kelompok kontrol dan perlakuan multipara. Terdapat perbedaan frekuensi respirasi yang bermakna antara sebelum observasi dengan sesudah observasi pada kelompok kontrol dan tidak terdapat perbedaan tekanan darah dan frekuensi nadi yang bermakna antara sebelum observasi dengan sesudah observasi pada kelompok kontrol. Terdapat perbedaan tekanan darah dan frekuensi nadi yang bermakna antara sebelum intervensi dengan sesudah intervensi pada kelompok perlakuan dan tidak terdapat perbedaan frekuensi respirasi yang bermakna antara sebelum intervensi dengan sesudah intervensi pada kelompok perlakuan. Terdapat perbedaan bermakna penurunan tekanan darah antara kelompok kontrol dengan perlakuan namun tidak terdapat perbedaan bermakna penurunan frekuensi nadi dan pernafasan antara kelompok kontrol dengan perlakuan

\section{SARAN}

Peneliti selanjutnya diharapkan dapat melakukan penelitian lebih lanjut dengan menambah variabel dependen penelitian (terapi psikologis) dan variabel independent (kadar hormone endhorpin) sehingga semakin memperkuat hasil penelitian untuk pengembangan inovasi intervensi kebidanan. Tenaga kesehatan diharapkan mulai menerapkan asuhan kebidanan maupun keperawatan dengan pemberian terapi nonfarmakologi sebagai terapi komplementer pilihan.

$$
\text { RSUD dr. R. Goeteng }
$$

Tarunadibrata Purbalingga diharapkan mulai merancang kebijakan atau program tentang pemberian terapi nonfarmakologis sebagai terapi komplementer (pendamping) dengan mempersiapkan sarana prasarana seperti: MP3, headset dan ruangan yang mendukung.

\section{UCAPAN TERIMAKASIH}

Peneliti menyampaikan terima kasih kepada: Kemenristek Dikti yang membiayai penelitian ini. Ketua STIKES Harapan Bangsa Purwokerto. Seluruh civitas STIKES Harapan Bangsa Purwokerto. RSUD dr. R. Goeteng Tarunadibrata Purbalingga yang ikut berpartisipasi dalam kegiatan riset.

\section{DAFTAR PUSTAKA}

American Music Therapy Association. (2008). Music therapy mental health-evidence based practice support

(http://www.music.therapy.org/fact sheet/b.b.psychopathology.pdf.

Arslan, S., Ozer, N., \& Ozyurt, F. (2008). Effect of music on preoperative anxiety in men undergoing urogenital surgery. Australian Journal of Advanced Nursing, 26(2): 46.

Cuningham, F.G. (2006). Obstetri Williams. Jakarta: EGC.

Dahlan, S. (2013). Statistika untuk kedokteran dan kesehatan. Jakarta : Salemba Medika.

Erkainen, H., A. (2007). Low Frequencies Research-Client Population and Annual Frequenxies Used. Sound Effects Annual.

Ernawati. (2013). Pengaruh Mendengarkan Murottal Q.S. Ar Rahman Terhadap Pola Tekanan Darah Pada Pasien Hipertensi di 
Rumah Sakit Nur Hidayah Yogyakarta. Skripsi. Program Studi IImu Keperawatan Fakultas Kedokteran dan IImu Kesehatan Universitas Muhammadiyah Yogyakarta.

Gunawan A.W. (2009). Hypnosis the art of subsconscious communication. Jakarta: Gramedia.

Izzat, A.M. \& Arif M. (2011). Terapi ayat Al Qur'an untuk Kesembuhan Keajaiban Al Qur'an Menyembuhkan Penyakit. Solo: Kafilah Publishing.

Jitowiyono, S. \& Kristiyanasari, W. (2010). Asuhan Keperawatan Neonatus Dan Anak Cetakan I. Jakarta: Nuha Medika.

Mahrifatulhijah. (2014). Pemeriksaan Tanda Vital. JKem-U, 6(16).

Mitas, A. W. (2009). Stimulation methods in music therapy-short discussion towards the bio-cybernetic aspect. Journal of Medical Informatics \& Technologies, 13.

Nafi'ah, R Z. (2015). Pengaruh pemberian murottal al-quran terhadap tekanan darah dan frekuensi denyut jantung pasien pasca operasi dengan anestesi umum di Rumah Sakit Umum Daerah Dr. Moewardi Surakarta. Skripsi. Fakultas IImu Kesehatan Universitas Muhammadiyah Surakarta.

Nurliana. (2011). Efektifitas Perangsangan Auditori Ayat-ayat Suci Al-Quran Terhadap Kecemasan Ibu Yang Sedang Dilakukan Kuret di RSUD Dr. Pringadi Medan.

Qadri, M. A. (2003). Quranic Therapy Heal Yourself. USA: Islamic Educational Cultural Research Center of North America.
Ras, W. A., dan Laird, L. (2011). How Muslim and Non Muslim Chaplains Serve Muslim patient? Does The Interfaith Chaplainy Model Have for Muslims Experience?" Religius Health.

Smeltzer, S.C, \& Bare, B. 2012. Brunner \& Suddarth buku ajar keperawatan medikal bedah, volume $1\left(12^{\text {th }}\right.$ ed.). Jakarta: EGC.

Sodikin. (2012). Pengaruh terapi bacaan Al Qur'an melalui media audio terhadap respon nyeri pasien post operasi hernia di RS Cilacap. http://garuda.dikti.go.id/jurnal/detil/ id/0:258176/q/pengarang:SODIKI N/offset/0/limit/15 diakses tanggal 15 April 2015.

Sunny, S. (2014). Gaya Bahasa dalam Surat Ar Rahman (Kajian Stilistika).. Tesis. UIN Sunan Kalijaga Yogyakarta.

Potter, P.A dan Perry A.G. (2010). Fundamentals of nursing. Jakarta: Salemba Medika.

Pramisiwi, et.al. (2011). Evidence Based Practice Intervensi Spiritual Keperawatan Melalui Murrotal Surah Ar-Rahman Untuk Menurunkan Cemas Di Ruang ICU dan IGD Rumah Sakit Islam Sultan Agung Semarang. Tidak dipublikasikan.

Scovell, S. (2010). Role of the nurse to nurse handover in patient care. Nursing Standard, 24(30): 35- 39.

Yuliatun, L. (2008). Penanganan nyeri persalinan dengan metode nonfarmakologi. Malang: Bayumedika 